\title{
Effect of posterior pericardial drainage on the incidence of pericardial effusion after ascending aortic surgery
}

Sadik Eryilmaz, MD, Ozan Emiroglu, MD, Zeynep Eyileten, MD, Ruchan Akar, MD, Levent Yazicioglu, MD, Refik Tasoz, MD, Bulent Kaya, MD, Adnan Uysalel, MD, Kemalettin Ucanok, MD, Tumer Corapcioglu, MD, and Umit Ozyurda, MD

From the Department of Cardiovascular Surgery, Ankara University, School of Medicine, Ankara, Turkey.

Received for publication Oct 25, 2005; revisions received Dec 30, 2005; accepted for publication Jan 13, 2006.

Address for reprints: Ozan Emiroglu, MD, Ankara University, School of Medicine, Department of Cardiovascular Surgery, Cebeci Kalp Merkezi, Dikimevi, 06620 Ankara, Turkey (E-mail: ozanemiroglu@mail.com).

J Thorac Cardiovasc Surg 2006;132:27-31

$0022-5223 / \$ 32.00$

Copyright $\odot 2006$ by The American Association for Thoracic Surgery

doi:10.1016/j.jtcvs.2006.01.049
Objective: Pericardial effusion and cardiac tamponade after ascending aortic surgery are higher than anticipated after cardiac surgery. We evaluated a thin closed-suction drain system to prevent posterior pericardial effusion in patients undergoing ascending aortic surgery.

Methods: One hundred forty patients who underwent ascending aortic surgery were prospectively randomized into group A and group B. In group A $(\mathrm{n}=70)$ we used a $32 \mathrm{~F}$ drain placed anteriorly overlying the heart and a $16 \mathrm{~F}$ thin drain placed retrocardially. In group B $(n=70)$ only a $32 \mathrm{~F}$ drain placed anteriorly was used. In group A we removed the large drain on the first postoperative day and continued drainage with the thin drain until the drainage was less than $50 \mathrm{~mL}$ in a 24-hour period. In group B we removed the drain after the first postoperative day when the drainage was less than $50 \mathrm{~mL}$ in an 8-hour period. Preoperative, perioperative, and postoperative parameters of the patients were compared.

Results: No significant posterior pericardial effusion and late cardiac tamponade developed in patients in group A. In group B $10(14.3 \%)$ patients experienced significant posterior pericardial effusion and $4(5.7 \%)$ patients experienced late cardiac tamponade; the incidence of significant pericardial effusion in group B was significantly higher $(P=.001)$. Postoperative new-onset atrial fibrillation developed in $6(10.4 \%)$ patients in group A and in $18(32.7 \%)$ patients in group B $(P=.03)$.

Conclusions: We demonstrated that effective posterior drainage is important to prevent posterior pericardial effusion, and use of a thin drain placed retrocardially appears to be sufficient for these results.

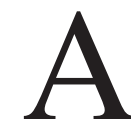
scending aortic surgery, which involves prolonged cardiopulmonary bypass and extensive dissection of the heart and the aorta, might be expected to give rise to a higher incidence of pericardial effusion and cardiac tamponade compared with other kinds of cardiac surgery (up to $31.6 \%$ and $15.7 \%$, respectively), and these procedures require long-term mediastinal drainage. ${ }^{1}$ The late significant pericardial effusion resulting in cardiac tamponade is frequently loculated in the posterior portion of the heart. ${ }^{2,3}$ Using large conventional drains (28F-32F) to prevent posterior effusions is inconvenient. In cases of prolonged drainage, because of the large diameter, they could be painful; they might limit self-ambulation not only to pain but also with their bulky fluid-collection devices. They might also cause an increase in the use of analgesic agents, and as the patient becomes more active, they might interfere with the heart and cause dysrhythmia. ${ }^{4,5}$

Although the problem in postoperative pericardial effusion in coronary artery bypass grafting or valve surgery had been solved, after ascending aortic surgery, it is still a problematic issue. We describe a method for mediastinal drainage after ascending aortic surgery involving the opportunity to remove the mediastinal large 


\section{Abbreviations and Acronyms \\ $\mathrm{SD}=$ standard deviation}

drain on the first postoperative day to minimize the anticipated complications and continue effective drainage with a thin closed-suction drain system to prevent posterior pericardial effusion.

\section{Materials and Methods}

Between January 1999 and July 2005, 140 patients who underwent replacement or repair of the ascending aorta with or without aortic valve replacement with diagnosis of type A dissection or ascending aortic aneurysms at our institution were included in this study. Patients were prospectively randomized into group A (70 patients) and group B (70 patients). The local ethical committee approved the study, and all patients provided written informed consent. Patients who had a history of prior sternotomy or cardiac surgery, who underwent concomitant bypass surgery, who were receiving any form of anticoagulation before surgical intervention, or who had a second operative procedure (apart from bleeding or tamponade) during the same hospital stay were excluded. Moreover, intraoperative and early hospital mortality were the exclusion criteria. We defined the status of the operation as elective, urgent, and emergency intervention. Elective cases were defined as patients operated on 48 hours after diagnosis. Urgent cases were defined as patients requiring operative intervention within 48 hours of diagnosis for acute or chronic type A aortic dissections, ascending aortic aneurysms causing intractable chest or back pain, and/or signs of obstruction or compression of the adjacent structures in the thorax. Emergency surgical cases were defined as patients requiring immediate operative intervention for acute aortic dissection or rupture causing signs of tamponade, severe aortic insufficiency, or continuous blood loss.

In group $\mathrm{A}$ we used a $32 \mathrm{~F}$ large conventional drain placed retrosternally in the anterior mediastinum overlying the heart and a $16 \mathrm{~F}$ thin closed-suction drain system (Redon drain system) placed toward the posterior pericardial cavity along the left ventricle in the retrocardiac cavity. In group B, as a control group, we used only a $32 \mathrm{~F}$ large conventional drain, which was placed anteriorly overlying the heart. Drains were placed in the mediastinum through a small incision several centimeters inferior to the lower pole of the median sternotomy wound. If one of the pleural spaces was opened, a third drain, sized $28 \mathrm{~F}$, was placed from the lateral thorax site into the pleural space.

In group A we removed the large drain on the first postoperative day and continued drainage with the thin drain that was placed retrocardially until the drainage was less than $50 \mathrm{~mL}$ in a 24-hour period to prevent late posterior pericardial effusion and cardiac tamponade. In group B we removed the drain after the first postoperative day when the drainage was less than $50 \mathrm{~mL}$ in an 8 -hour period. Drain outputs were recorded hourly for the first 2 days and daily for the following days. No data were recorded from pleural space drains because we removed them as soon as the chest radiographs showed no signs of pneumothorax on postoperative day 1.
Groups were compared for preoperative, intraoperative, and postoperative characteristics; drainage in the first 24 hours; total amount of drainage; time of drain removal after the operation; length of postoperative stay; incidence of postoperative pericardial effusion; cardiac tamponade; re-exploration; and drain-associated infection. Moreover, on the morning of postoperative days 1, 2, and 3 , patients were asked by nurses whether they had any complaints about their drains, and they were asked to simply answer as "no," "little," "moderate," or "severe." Patients for whom the drains were removed had their answers recorded as "no discomfort."

The efficacy of drains in both groups was determined with chest radiography and 2-dimensional transthoracic echocardiography. The same echocardiographer, who was not informed about the study, performed echocardiographic examinations. In-hospital chest radiographs were routinely performed on the first and second postoperative days and subsequently if dictated by the individual patient's symptoms. Echocardiography of the pericardium was routinely performed on postoperative days 1 and 7 to measure the size and type of pericardial effusions. A pericardial effusion is classified as anterior, posterior, or circumferential, and those with a size equal to or larger than $10 \mathrm{~mm}$ were considered significant. In the evaluations pericardial effusion or cardiac tamponade that developed in the first postoperative week was defined as "early," and that developing after the first postoperative week was defined as "late." Patients with pericardial effusion $(5-10 \mathrm{~mm})$ on postoperative day 7, chest radiography with signs or clinical suspicions of late pericardial effusion, or cardiac tamponade after the first postoperative week were re-evaluated with echocardiography.

Characteristics are described as means and standard deviations (SDs) or as percentages. Nominal variables were analyzed by using $\chi^{2}$ or Fisher exact tests, where applicable. Comparisons between groups for normally distributed continuous variables were evaluated by using the Student $t$ test. The Mann-Whitney $U$ test was used for ordinal variables to compare groups.

\section{Results}

A total of 140 patients were included in the study. Group A, with the thin drain, consisted of 70 patients (29 men and 41 women) with a mean \pm SD age of $55.5 \pm 7.3$ years (median, 57 years; minimum-maximum, 38-68 years), and group B, with conventional drains, included 70 patients (32 men and 38 women) with a mean \pm SD age of $54.6 \pm 7.5$ years (median, 55 years; minimum-maximum, 39-67 years). Patients with moderate-to-severe aortic regurgitation underwent aortic root replacement with aortic valve replacement using a composite valve-graft conduit (the Bentall procedure), and where the aortic valve could be repaired, valvesparing procedures were performed with ascending aortic replacement with a tube graft of appropriate size. All surgical procedures were performed during $\mathrm{CPB}$. There was no statistical significance with regard to the type $(P=.461$, $P=.546$, and $P=.680)$ and status $(P=.606, P=.855$, and $P=.260)$ of the surgical procedures performed between the 2 groups (Table 1). All patients who had the aortic valve replaced with a conduit valve-composite graft (the Bentall procedure) were started on warfarin to maintain an 
TABLE 1. Preoperative, intraoperative, and postoperative characteristics

\begin{tabular}{|c|c|c|c|}
\hline Variable & Group A (n = 70) & Group B $(\mathbf{n}=70)$ & $P$ value \\
\hline Age (y) & $55.3 \pm 7.3$ & $55.7 \pm 7.5$ & .716 \\
\hline Sex (male/female) & $29 / 41$ & $32 / 38$ & .609 \\
\hline Preoperative Htc $(\%)$ & $38.9 \pm 5.8$ & $39.8 \pm 4.5$ & .314 \\
\hline Bentall procedure (n [\%]) & $51(72.9)$ & $47(67.1)$ & .461 \\
\hline Valve-sparing procedure + AAR (n [\%]) & $5(7.1)$ & $7(10.0)$ & .546 \\
\hline AAR (n [\%]) & $14(20.0)$ & $16(22.9)$ & .680 \\
\hline Elective (n [\%]) & $43(61.4)$ & $40(57.1)$ & .606 \\
\hline Urgent (n [\%]) & $22(31.4)$ & $21(30.0)$ & .855 \\
\hline Emergency (n [\%]) & $5(7.1)$ & $9(12.9)$ & .260 \\
\hline Surgical use of antifibrinolytics (n [\%]) & $55(78.6)$ & $49(70.0)$ & .246 \\
\hline Cardiopulmonary bypass time (min) & $170.7 \pm 21.8$ & $175.6 \pm 19.3$ & .157 \\
\hline PO Positive inotropic support (n [\%]) & $27(38.6)$ & $23(32.9)$ & .480 \\
\hline Re-exploration for bleeding (n [\%]) & $2(2.9)$ & $3(4.3)$ & 1.000 \\
\hline Re-exploration for tamponade (n [\%]) & $2(2.9)$ & $2(2.9)$ & 1.000 \\
\hline Drain-associated infection (n [\%]) & $0(0)$ & $0(0)$ & - \\
\hline PO hospital Stay (d) & $9.0 \pm 2.5$ & $10.3 \pm 2.9$ & .003 \\
\hline
\end{tabular}

Htc, Hematocrit; $A A R$, ascending aortic replacement; $P O$, postoperative.

international normalized ratio of between 2.5 and 3.5 times control values. The patients who underwent ascending aortic replacement without aortic valve replacement did not receive any form of postoperative anticoagulation.

Two (2.9\%) patients in group A and $3(4.3 \%)$ patients in group B underwent re-exploration for bleeding in the first postoperative 6 hours. Two patients in each group underwent re-exploration for early tamponade because of bleeding in the first postoperative 24 hours. There were $2(2.9 \%)$ patients in group A and $1(1.4 \%)$ patient in group B with mediastinal wound infection $(P=1.000)$. There were no episodes of drain-site infection or sepsis related to the use of drains in both groups. Patients in group A were discharged after a mean \pm SD of $9.0 \pm 2.5$ days (range, 6-16 days), and patients in group B were discharged after a mean \pm SD of 10.3 \pm 2.9 days (range, 6-18 days). The long lengths of hospital stay were related to the development of significant pericardial effusion, cardiac tamponade, medical complications like high international normalized ratio values, postoperative new-onset arrhythmias, and postoperative mediastinal wound infections. The preoperative, intraoperative, and postoperative characteristics of the 2 groups are shown in Table 1.

We removed the large drains after $17.9 \pm 2.6$ hours in group A and $52.1 \pm 11.5$ hours in group B $(P<.001)$. The mean \pm SD mediastinal drainage values in the first 24 hours in groups A and B were 539.2 \pm 144.2 and $527.8 \pm 131.1$ $\mathrm{mL}$, respectively $(P=.326)$. There were 14 patients in group A and 10 patients in group B with pleural space drains (20\% vs $14.3 \%, P=.370)$, and we removed them after $20.3 \pm 5.1$ hours in group A and $19.1 \pm 4.8$ hours in group B $(P=.08)$. Parameters of drains are summarized in Table 2.
Early pericardial effusion developed in $2(2.9 \%)$ patients in group A and 2 (2.9\%) patients in Group B. Patients in group A did not respond to conservative medical therapy, and there was no reduction in the size of pericardial effusions. They were treated with echocardiography-guided percutaneous pericardiocentesis. Twelve (17.1\%) patients from group B had late posterior pericardial effusion, whereas no patients had late posterior pericardial effusion in group A; the difference was statistically different $(P<.001)$. Among 12 patients who had late posterior pericardial effusion in group B, 10 were treated conservatively; 2 patients who did not respond to conservative medical therapy clinically worsened and were drained percutaneously. Four (5.7\%) patients from group B had late posterior cardiac tamponade that was drained percutaneously. Two of these patients had been previously discharged from the hospital after surgical intervention and required readmission. None of the patients had late cardiac tamponade in group A $(5.7 \%$ vs $0 \%, P=.120)$. Early and late postoperative transthoracic echocardiographic evaluations and $P$ values are summarized in Table 3 .

When patients in groups A and B were questioned about whether they had any complaints about the drains on post-

TABLE 2. Parameters of drains

\begin{tabular}{lccc}
\hline Variable & $\begin{array}{c}\text { Group A } \\
(\mathbf{n}=\mathbf{7 0})\end{array}$ & $\begin{array}{c}\text { Group B } \\
(\mathbf{n}=\mathbf{7 0})\end{array}$ & $\begin{array}{c}\boldsymbol{P} \\
\text { value }\end{array}$ \\
\hline Duration of large drain (h) & $17.9 \pm 2.6$ & $52.1 \pm 11.5$ & $<.001$ \\
Duration of thin drain (d) & $2.7 \pm 0.7$ & - & - \\
Drainage, first 24 h $(\mathrm{mL})$ & $539.2 \pm 144.2$ & $527.8 \pm 131.1$ & .326 \\
Total drainage $(\mathrm{mL})$ & $679.7 \pm 154.3$ & $675.4 \pm 149.5$ & .884 \\
\hline
\end{tabular}


TABLE 3. Postoperative echocardiographic evaluations

\begin{tabular}{lccr}
\hline Variable & $\begin{array}{c}\text { Group A } \\
(\mathbf{n}=\mathbf{7 0})\end{array}$ & $\begin{array}{c}\text { Group B } \\
(\mathbf{n}=\mathbf{7 0})\end{array}$ & $\begin{array}{c}\boldsymbol{P} \\
\text { value }\end{array}$ \\
\hline Early anterior PE (n [\%]) & $2(2.9)$ & $1(1.4)$ & 1.000 \\
Early posterior PE (n [\%]) & $0(0)$ & $3(4.3)$ & .245 \\
Early circumferential PE (n [\%]) & $0(0)$ & $1(1.4)$ & 1.000 \\
Late anterior PE (n [\%]) & $2(2.9)$ & $3(4.3)$ & 1.000 \\
Late posterior PE (n [\%]) & $0(0)$ & $10(14.3)$ & 0.001 \\
Late circumferential PE (n [\%]) & $0(0)$ & $1(1.4)$ & 1.000 \\
Late posterior CT (n [\%]) & $0(0)$ & $4(5.7)$ & .120 \\
\hline
\end{tabular}

$P E$, Pericardial effusion; $C T$, cardiac tamponade.

operative days 1,2, and 3 and they were asked to given answers of "no," "little," "moderate," or "severe" discomfort, the answers were as summarized in Figure 1. When answers of "severe discomfort" from groups A and B were compared by using $\chi^{2}$ tests on postoperative days 1,2 , and 3 , the results were $P$ values of less than .001 , less than .001 and less than .001 , respectively. On postoperative days 1 and 2, the patient's discomfort levels were significantly lower in group A.

When we were analyzing the possible side effects of the drains, we documented postoperative new-onset arrhythmias. When we excluded patients with preoperative arrhythmias, in this study we found that in group A, of 58 patients, there were $6(10.4 \%)$ with postoperative new-onset atrial fibrillation. In group B, of 55 patients, 18 (32.7\%) had postoperative new-onset atrial fibrillation, and the incidence of new-onset postoperative arrhythmias in group A was significantly lower than that of postoperative arrhythmias in group $\mathrm{B}(P=.03)$.

\section{Discussion}

The incidence of significant pericardial effusion after cardiac surgery in the literature is between $1 \%$ and $6 \% .^{6-8}$ However, after ascending aortic surgery, the incidence of significant pericardial effusion is up to $35 \%$ and that of cardiac tamponade is as high as $15.7 \% .^{1}$ Previous studies have related postoperative pericardial effusion to excessive postoperative mediastinal drainage and postpericardiotomy syndrome. Stevenson and colleagues ${ }^{8}$ determined that pericardial effusions were more likely to develop if there was significant postoperative bleeding, greater than $500 \mathrm{~mL}$, in the first postoperative 24 hours. The amount of surgical dissection and the length and complexity of the operation might account for a higher than average incidence of blood loss after aortic root surgery, and this could relate to an increased risk of pericardial effusion and cardiac tamponade. In our study the mean mediastinal drainage in the first 24 hours in groups A and B were both greater than $500 \mathrm{~mL}$, and in the control group, group B, there were 19 patients with significant postoperative pericardial effusion. Therefore in our study the incidence of significant pericardial effusion after aortic root surgery was $27.1 \%$. Furthermore, in group B 2 patients underwent reoperation for early cardiac tamponade because of excessive bleeding, and there were 4 patients who had late posterior cardiac tamponade; the incidence of postoperative cardiac tamponade was calculated as 8.6\%. Our results correlate with the high incidence of pericardial effusion and cardiac tamponade after aortic root surgery in the study by Alkhulaifi and associates. ${ }^{1}$

In this study we removed the large drains on postoperative day 1 to prevent the anticipated large drain complications and continued draining with a thin drain, with the idea to drain the posterior of the heart completely once the patient has been mobilized and to prevent late posterior pericardial effusion and cardiac tamponade. The main reason to place the thin drain retrocardially is to prevent pericardial effusion that is often loculated at the posterior of the left ventricular wall. The pericardial effusion loculated anterior of the heart is easily drained from a chest drain placed anteriorly. However, because pericardial adhesions are frequently observed in between the inferior-posterior surface of the heart and the diaphragm, they might cause an enclosed gap and make drainage difficult. The results reported in our study demonstrate that continuing drainage with thin closed-suction drain systems are effective for draining the posterior of the heart, thus preventing posterior pericardial effusion in patients undergoing ascending aortic surgery.

The uses of thin drains in the chest drainage have been reported before. The experience to date suggests that the use of thin drains is as effective as the use of large drains. ${ }^{9}$ Our results have shown that there is no increased risk of bleeding, cardiac tamponade, or infection associated with the use

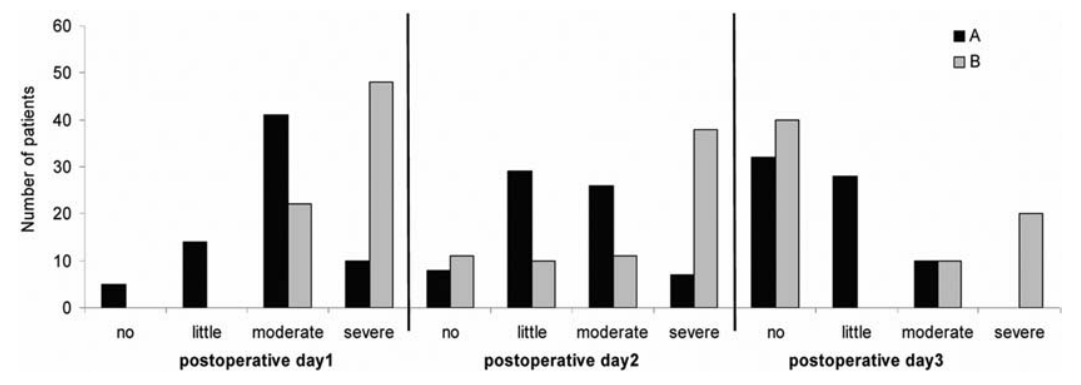

Figure 1. Comparison of complaints about drains in groups $A$ and $B$. 
of a thin closed-suction drain system. We analyzed our results to determine whether there would be undesirable results like arrhythmia caused by cardiac irritation after placing the thin drain in the retrocardiac cavity. However, interestingly, we found out that in group A, with a thin drain, the incidence of new-onset postoperative arrhythmias was significantly lower than that in group B. Angelini and coworkers ${ }^{10}$ presented refractory (to medication and cardioversion) postoperative arrhythmias caused by pericardial effusion after cardiac surgery that responded well to the evacuation of the effusion and a consequent sinus rhythm. Previous efforts have been done to reduce the incidence of postoperative posterior pericardial effusion and therefore postoperative arrhythmias. ${ }^{11}$ In our study the incidence of postoperative pericardial effusion was lower in group A, and this is probably why we observed a lower incidence of postoperative new-onset atrial fibrillation in this group. However, as in this study, our primary goal was not to investigate postoperative arrhythmias. Further studies should be performed, and we believe that this study will be a pioneer for future similar studies.

It is difficult to evaluate scientifically the level of discomfort felt by patients, and it cannot provide accurate information on patients' actual complaints. Furthermore, patients' perceptions of outcome are important, and we must give attention to any complaints about drains. Large drains are painful, and in aortic root surgery, prolonged drainage is frequently unavoidable. By our own observations, removing the large drains and continuing drainage with the thin drain after postoperative day 1 is much more comfortable and appears to permit earlier ambulation, resulting in improved pulmonary toilet.

One of the limitations of the study is that the doctors, nurses, and (although she was not informed about the study) the echocardiographer were not blinded to the type of drain method used.

We demonstrated that effective posterior drainage is important in ascending aortic surgery, and it reduces not only the high incidence of late significant pericardial effusion but also might reduce early pericardial effusion and related postoperative arrhythmias. We also demonstrated that use of a thin closed-suction drain placed retrocardially is simple and safe and appears to be sufficient for posterior drainage.

We thank the biostatistician, Dr Atilla H. Elhan, Ankara University, for the support given regarding the statistical analysis. We also thank all the staff involved in patient care and the nurses who recorded the data of these patients at the Department of Cardiovascular Surgery of Ankara University.

\section{References}

1. Alkhulaifi AM, Speechly-Dick ME, Swanton RH, Pattison W, Pugsley WB. The incidence of significant pericardial effusion and tamponade following major aortic root surgery. J Cardiovasc Surg. 1996;37: 385-9.

2. Pepi M, Muratori M, Barbier P, Doria E, Arena V, Berti M, et al. Pericardial effusion after cardiac surgery: incidence, site, size and hemodynamic consequences. Br Heart J. 1994;72:327-31.

3. Chuttani K, Tischler MD, Pandian NG, Lee RT, Mohanty PK. Diagnosis of cardiac tamponade after cardiac surgery: relative value of clinical, echocardiographic and hemodynamic signs. Am Heart J. 1994;127:913-8.

4. Mueller XM, Tinguely F, Tevaearai HT, Ravussin P, Stumpe F, Segesser LK. Impact of duration of chest tube drainage on pain after cardiac surgery. Eur J Cardiothorac Surg. 2000;18:570-4.

5. Kollef MH, Dothager DW. Reversible cardiogenic shock due to chest tube compression of the right ventricle. Chest. 1991;99:976-80.

6. Ofori-Krakye SK, Tyberg TI, Geha AS, Hammond GL, Cohen LS, Langou RA. Late cardiac tamponade after open heart surgery: incidence, role of anticoagulants in its pathogenesis and its relationship to the post-pericadiotomy syndrome. Circulation. 1981;61:1323-8.

7. Kuvin JT, Harati NA, Pandian NG, Bojar RM, Khabbaz KR. Postoperative cardiac tamponade in the modern surgical era. Ann Thorac Surg. 2002;74:1148-53.

8. Steveson LW, Child JS, Laks H, Kern L. Incidence and significance of early pericardial effusions after cardiac surgery. Am J Cardiol. 1984; 54:848-51.

9. Akowuah E, Ho EC, George R, Brennan K, Tennant S, Braidley P, et al. Less pain with flexible fluted silicone chest drains than with conventional rigid chest tubes after cardiac surgery. J Thorac Cardiovasc Surg. 2002;124:1027-8.

10. Angelini GD, Bryan AJ, Lamarra M. Refractory supra-ventricular tachyarrhythmias due to early posterior pericardial effusion following open heart surgery. Thorac Cardiovasc Surg. 1988;36:162-3.

11. Mulay A, Kirk MB, Angelini GD, Wishheart ID, Hutter JA. Posterior pericardiotomy reduces the incidence supraventricular arrhythmias following coronary artery bypass surgery. Eur J Cardiothorac Surg. 1995;9:150-2. 